\title{
Sangue da terra: as trajetórias de humanos, insetos e plantas e a presunção antropocêntrica
}

doi https://doi.org/10.21814/anthropocenica.3167

\author{
Mateus Amoedo Zani \\ Instituto Federal de Educação Ciência e Tecnologia de São Paulo - IFSP. \\ Brasil. \\ profmateuszani@gmail.com \\ ORCID: 0000-0001-7946-6820
}

\begin{abstract}
Resumo
O presente artigo percorre a trajetória de humanos e não-humanos, insetos cochonilha e suas plantas hospedeiras, a fim de demonstrar que a pretensão de controle humano sobre o comportamento de nãohumanos é apenas aparente e, certamente, um perigoso engano. Após a última virada de século uma espécie de cochonilha devastou plantações de palma forrageira no semiárido brasileiro. Pernambuco e Paraíba tiveram quase $100 \%$ das lavouras destruídas. Já em outros contextos do mundo, os papéis se invertem e a mesma palma forrageira é que era vista enquanto praga e as cochonilhas, por sua vez, eram importadas para fins de controle biológico. Com o tempo, tais insetos se tornaram a própria praga a destruir as plantações, com sua presença notificada em diversos países ao redor do mundo.
\end{abstract}

Palavras-chave

Cochonilhas; palma forrageira; Dactylopius spp.; Opuntia spp.; vermelho carmim; não-humanos.

\begin{abstract}
The present article traces the trajectory of humans and nonhumans, mealybugs insects and their host plants, in order to demonstrate that the claim of human control over the behavior of nonhumans is only apparent and certainly a dangerous mistake. After the last turn of the century, a cochineal species devastated the forage palm plantations in the Brazilian semiarid region. Pernambuco and Paraíba had almost $100 \%$ of the crops destroyed. In other contexts in the world, the roles were reversed and the same forage palm was seen as a pest and scale insects, in turn, were imported for biological control purposes. However, over time, these insects have become the plague itself to destroy crops, with their presence reported in several countries around the world.
\end{abstract}

Keywords

Cochineals; prickly pear; Dactylopius spp.; Opuntia spp.; carmine dye; non-humans.

\section{Introdução}

No início deste século uma grave crise provocada por um inseto-praga atingiu produtores de bovinos, ovinos e caprinos na região do semiárido brasileiro. A perda de quase $100 \%$ das plantações de palma forrageira (Chiacchio, 2008, p. 12) ocasionou uma drástica redução dos rebanhos da região (Instituto Brasileiro de Geografia e Estatística, 1970 e 2006) e, ao iniciar em 2017 
o trabalho de campo que deu origem a este artigo ${ }^{1}$, os sitiantes entrevistados na região do Cariri Paraibano encontravam-se com sérias dificuldades para obter a ração de seus animais. Isso pois, tal praga se propagou concomitante a um longo período de estiagem com início em 2011 e término apenas em 2018. No decorrer desse processo, as plantações de palma forrageira da espécie Opuntia ficus-índica foram completamente devastadas pela rápida proliferação do inseto Dactylopius opuntiae, deixando os produtores sem reservas de forragem para a ração de seus animais.

Neste contexto em que atores não-humanos participam tão decisivamente do processo histórico, o presente artigo objetiva mostrar, através da trajetória completamente entrelaçada de humanos, insetos e plantas cacto, que a pretensão dos humanos de domínio e controle sobre o comportamento de outras formas de vida mostra-se no percurso desta experiência uma concepção enganosa da relação entre tais atores não apenas no semiárido brasileiro, como em outras partes do mundo. Há, tal como define Luiz Marques (2015, p. 550), uma presunção antropocêntrica de "superioridade e finalidade", o humano como superior e enquanto fim em si mesmo de tudo o que existe e ocorre no mundo. Por outro lado, como demonstra o autor, há um "retorno negativo" que pode ser observado na resistência de outras formas de vida a se submeterem ao controle humano. Se no presente artigo são analisadas as trajetórias de insetos e plantas, Luiz Marques apresenta como um dos muitos "efeitos de retorno negativo" a seleção de bactérias super-resistentes a antibióticos, que aumentam rapidamente quanto mais os humanos insistem na administração rotineira do medicamento. Ainda neste sentido, é importante lembrar que em 2020 populações de todo o mundo foram levadas ao isolamento de suas casas como medida de controle sanitário de uma pandemia provocada pelo vírus SARS-CoV2. Ou seja, em pouquíssimo tempo desde que o primeiro caso foi noticiado, uma forma de vida invisível aos olhos humanos foi capaz de mudar drasticamente a história da humanidade.

Tal como as bactérias super-resistentes ou o vírus de alta transmissibilidade, no caso apresentado neste trabalho, evidencia-se que ao longo de séculos os humanos buscaram manter sob seu controle (por sua presunção de superioridade e finalidade do mundo) cactos e insetos, que por sua vez apresentaram-se por inúmeras vezes ao longo destas trajetórias não apenas resistentes a esse domínio absoluto, como também atores livres desta mesma história. Para isso, o texto percorre um longo caminho de rastros dos personagens, desde a domesticação de plantas e insetos pelas populações précolombianas, passando pela grande relevância económica que essas tiveram para o reino espanhol, do Renascimento ao século XIX, como também, a

\footnotetext{
10 presente estudo tem origem em pesquisas bibliográficas e trabalhos de campo realizados entre sitiantes da cidade de Boa Vista - PB, entre 2017 e 2018 no contexto da pesquisa de campo para o doutorado em Antropologia Social.
} 
utilização dos insetos para fins de controle biológico² de cactos palma enquanto espécie invasora em alguns países do mundo, a retomada do interesse comercial nos cactos e insetos impulsionada pela indústria de alimentos, e, por fim, a grave crise que afetou a região semiárida do Brasil na última década.

Duas espécies de cactos e duas espécies de insetos cochonilha ${ }^{3}$ ganham destaque no presente artigo: 1) Dactylopius coccus é uma espécie de cochonilha com valor comercial por ser fonte para a produção de uma tintura de tonalidade vermelho profundo, o vermelho carmim, o que the confere o nome de cochonilhado-carmim; a espécie foi domesticada pelos Astecas e a tintura vermelha obtida através desses insetos, chamada na língua nativa de "nochetztli, ou seja, 'sangue da terra'”, era utilizada para diversos fins (Ferraz, 2007, p. 1032); 2) A espécie Dactylopius opuntiae também produz o vermelho carmim, porém sua rápida reprodução e capacidade de predação das plantas hospedeiras fez dessa espécie um eficiente agente de controle biológico de cactos palma em vários países do mundo; ou seja, duas espécies de insetos da mesma família (Dactylopiidae), mas com papéis muito diferentes na história - os cactos palma em questão seriam: 1) Opuntia ficus-índica, chamada de Palma Gigante pelos sitiantes da Paraíba (hospedeira para ambas as espécies de insetos; amplamente cultivada ao redor do mundo desde o Renascimento e de grande importância enquanto forragem para bovino, ovino e caprinocultores no semiárido brasileiro; 2) Opuntia stricta, conhecida também como Orelha-deelefante-mexicana ou Palma Resistente (por não servir de hospedeira para os referidos insetos, a espécie foi introduzida no Brasil após as plantações da primeira terem sido atacadas e mortas pela ação do Dactylopius opuntiae).

\section{A ilusão antropocêntrica de controle da esfera natural}

Tem sido recorrente na história do semiárido a falência de certos modos de organizar a vida nos sítios em consequência de pragas que destruíram lavouras e experiências que prometiam a solução para os problemas económicos da região. Assim, por exemplo, foi implantado o cultivo da Algaroba, árvore de origem exógena que é capaz de buscar água em longas distâncias e superar obstáculos para alcançá-la, mantendo-se verde ao longo dos períodos de estiagem. Porém, a mesma acabou por se espalhar não apenas pela área rural, como também nas áreas urbanas, ocasionando a morte das plantas

\footnotetext{
2 Controle biológico se refere à restrição da proliferação de populações de animais e plantas através de agentes bióticos, ou seja, o manejo demográfico é realizado por, ou através de, inimigos naturais. Pode ser tanto um fenômeno natural como uma estratégia humana para o manejo de pragas (Bueno et al., 2015).

3 Segundo Chávez-Moreno e Casas (2009, p. 3338) existem nove espécies da família Dactylopiidae, sendo elas: "Dactylopius ceylonicus, D. coccus, D. confusus, D. opuntiae, D. tomentosus, D. austrinus, D. confertus, D. salmianus and D. zimmermanni"; e menciona que apesar de alguns autores considerem $D$. bassi como uma décima espécie não há consenso sobre a questão.
} 
nativas ao seu redor, tornando-se problema para os habitantes (Burnett, 2017; Pegado et al., 2006). Já no caso do algodoeiro, que já foi a base da economia desta região, seu cultivo teve que ser abandonado após as plantações serem praticamente devastadas por uma praga chamada de bicudo-do-algodoeiro (Anthonomus grandis) (Miranda \& Rodrigues, 2015).

As alternativas para convivência com o semiárido são sempre aquelas que melhor se adaptam às variações das estações climáticas na região (sendo a seca - período de estiagem e o inverno - período chuvoso). Motivo pelo qual o cultivo de palma forrageira, planta plenamente adaptada a tais condições, se faz extremamente importante para a produção rural neste contexto (Galvão Junior et al., 2014, p. 79). Pesquisas comprovam suas qualidades, tais como: a) o armazenamento de água, "mucilagem e resíduo mineral; b) apresentam alto coeficiente de digestibilidade da matéria seca e c) têm alta produtividade" (Lopes et al, 2009). Além disso, outro fator que facilita sua manutenção, mesmo em períodos de estiagem, é que "essas plantas geralmente abrem seus estômatos durante a noite e os fecham durante o dia, (e) desta forma minimizam a perda de água" (p. 197), assim, elas absorvem a umidade noturna e evitam a perda sob o calor do sol (Santos et al., 2017, n.p.). Qualidades essas que fizeram do cultivo da palma forrageira, em especial a 0 . ficus-índica, prática basilar para a manutenção da pecuária bovina, ovina e caprina no semiárido.

Em 2010 o semiárido nordestino (com 8,4 milhões de habitante na área rural) contava com a maior área de cultivo da espécie em todo mundo, com cerca de 500 mil hectares, os quais alimentavam 10 milhões de caprinos e ovinos (Lopes et al., 2010, p. 205). Tamanha é a relevância das lavouras de palma forrageira para a pecuária nesta região que é possível afirmar que a proliferação de $D$. opuntiae alterou o rumo da história de todos os habitantes, sejam eles humanos ou não.

Neste sentido das profundas transformações de que são capazes os atores não humanos da vida coletiva, Graham Harman (2009), em seu livro Prince of Network: Bruno Latour and Metaphysics, dá uma definição alegórica muito precisa sobre o lugar que a ação dos não-humanos ocupa na base teórica do antropólogo francês e que ajuda a pensar o caso em questão:

Qualquer tentativa de ver os atores como marionetes redutíveis de estruturas mais profundas está fadada ao fracasso. 0 equilíbrio de forças faz com que alguns atores sejam mais fortes que outros, porém objetos enganadores (trickster) em miniatura mudam a maré sem aviso: um seixo pode destruir um império caso o Imperador se engasgue ao jantar (Harman, 2009, p. 21; tradução minha).

Assim, percebe-se que, de acordo com Harman, Bruno Latour busca superar a ideia de que existam sociedades humanas cercadas por instrumentos manipuláveis (ou insetos e plantas manipuláveis, no caso específico aqui 
analisado). Um mundo de objetos inanimados aguardando pela intervenção humana ou como peças figurativas, apenas cenário para a atuação dos humanos. Um mundo de materiais que, quando muito, ganham algum destaque como entraves a serem subordinados e superados pela razão e ação destes mesmos humanos.

Neste mesmo sentido, há ainda a interessante visão de Tim Ingold (2012), que cita um facto muito significativo para se analisar fluxos de não-humanos e o pretendido (ou suposto) controle humano sobre tais fluxos. Refere-se Ingold ao trabalho de pintores que exerciam, de certa forma, o trabalho de alquimistas intentando através da manipulação de materiais criar a matéria-prima de sua arte. Quanto aos pigmentos, Ingold menciona que certa tonalidade de vermelho seria obtida através de "pequenos insetos avermelhados que eram fervidos e secos ao sol para produzir o vermelho profundo conhecido como carmim" (Ingold, 2012, p. 36). Esses insetos passaram a ser valorizados pelo potencial do corante obtido através deles e desde o renascimento esta teria passado a ser a fonte de vermelho profundo mais utilizada em obras de arte em Portugal (Cruz, 2007, p. 43). Ao escrever seu artigo, Ingold ainda não sabia a forma como tais insetos participavam decisivamente dos rumos da história ao redor do mundo. 0 que o autor argumenta é que na sua atividade em laboratório o que se faz na verdade é "reunir materiais diversos", "combinar e redirecionar seu fluxo tentando antecipar aquilo que irá emergir" (Ingold, 2012, p. 36). 0 que mostra o presente artigo, para além do ambiente do laboratório, é que o fluxo dos nãohumanos, materiais, plantas, insetos, em toda sua complexidade, nem sempre pode ser antecipado. Ou seja, como afirma Ingold (2012), há a pretensão de humanos em demonstrar "uma aparência de controle sobre o que passa" (Ingold, 2012, p. 35), a aparência de controle humano sobre o fluxo dos não-humanos, algo que não condiz exatamente com a realidade.

Apesar das divergências existentes entre as teorias de Ingold e Latour, principalmente por parte do primeiro (Ingold, 2012; Ingold, 2015), há, como bem observa Otávio Velho (2012, p. 228) "afinidades" que podem e devem ser exploradas. Bruno Latour, por exemplo, mesmo que por caminho diferente do adotado por Ingold, faz semelhante afirmação ao defender o que chamou de "testemunho dos não-humanos" no laboratório científico. Dizia ele que "a velha hermenêutica irá continuar, mas ela acrescentará a seus pergaminhos a assinatura trêmula dos instrumentos científicos" (Latour, 1994, pp. 28-29). Na proposta de abordagem de Latour, aqueles que sempre foram tidos apenas como instrumentos, passam a ser atores do processo de conhecimento e, portanto, do processo histórico.

Enquanto fonte de vermelho carmim, as cochonilhas provocaram uma relevante transformação na produção dos corantes dessa tonalidade desde as primeiras viagens dos espanhóis à América Central. Há a possibilidade até mesmo de que Colombo o tenha levado consigo para Lisboa já em sua primeira 
viagem (Griffith, 2004, p. 1915). No entanto, mesmo que tenha levado consigo tais insetos, o método de obtenção do pigmento era mantido em segredo pelos Astecas (Ferraz, 2007, p. 1032). Devido à possibilidade de ser utilizado em atividades diversas, como na pintura, na fabricação de roupas, de alimentos, entre outros fins, além da boa produtividade, essas cochonilhas logo ganharam grande importância no mercado europeu, como assevera Ferraz (2007):

Ao se dar conta da importância desse material, o governo espanhol ordenou, ainda no século XVI, a busca de informações sobre como obter esse produto que, enviado à Castela, poderia gerar grandes lucros. Uma ordenação de Felipe III - rei de Espanha e Portugal entre 1598-1621 - deixa clara a importância do corante ao considerá-lo: "...um dos mais caros frutos que se criam em nossas Índias Ocidentais [...], mercadoria que se equipara ao ouro e à prata" ( $p$. 1032).

A produção espanhola de corante carmim foi estabelecida na região de Oaxaca e, para se ter uma referência dos valores, destinou para a metrópole uma média de 700 toneladas do produto por ano entre 1760 e 1850 (Chávez-Moreno et al., 2009, p. 3346). Por ser uma mercadoria tão valiosa, os espanhóis também tomaram medidas para evitar que outros governos descobrissem sua fórmula e tal fato veio seguido de projetos de espionagem que vislumbravam desvelar tal segredo. Destaque para a campanha de N. J. Thiéry de Menonville (1739-1780), que conseguiu se infiltrar entre os nativos e espanhóis passando por um pesquisador interessado nas plantas nativas com a finalidade de herborizá-las em outros locais, assim como, atendia como médico aqueles que o procuravam durante sua viagem Como resultado da experiência de investigação, Thiéry de Menonville publicou mais tarde suas memórias e uma completa descrição das palmas hospedeiras e dos métodos de obtenção do corante (Ferraz, 2007, pp. 1032-1037).

O trabalho foi traduzido para o português em 1799 e chegou ao Brasil através de publicações que visavam promover a produção e comércio da tintura no então território do reino de Portugal. Isso, tendo em vista que "Portugal esteve, particularmente, desde a Idade Média, ligado à tinturaria pelas artes e técnicas de tingimento e pelas rotas de comercialização de tintos naturais" (Paixão, 2007, pp. 6-7), além de que o corante de cochonilha se mostrou eficiente no tingimento da seda dos famosos bordados portugueses de Castelo Branco.

Neste contexto, os portugueses enviaram em 1798 o brasileiro Hipólito José da Costa para, de alguma forma, tentar "repetir o que Thiéry de Menonville fizera cerca de 20 anos antes" (Ferraz, 2007, p. 1034). As descrições nada acrescentaram ao já documentado por Menonville, mas demonstram o interesse do Reino de Portugal na produção da cochonilha nas terras do Brasil em tentativas que se seguiram infrutíferas ainda pelo século seguinte (Ferraz, 2007, 
p. 1035), já após a Independência e o início do período do Império no Brasil. Devido ao insucesso na produção do corante, as palmas só voltaram à pauta do Estado brasileiro no início da década de 1930, quando, "após uma seca severa atingir a região semiárida do Nordeste do Brasil, o Governo Federal encorajou a produção de cactos palma para a ração animal" (Torres \& Giorgi, 2018, p. 331). Segundo o historiador Frederico de Castro Neves (2001), a seca de 1932 marca uma importante mudança nas relações políticas entre a população, as oligarquias regionais e o Estado no sentido de uma coordenação e centralização das intervenções públicas durante a estiagem. Desde então, o cultivo das palmas se tornou indispensável para os produtores de bovinos, ovinos e caprinos e o Brasil passou a ter a maior área cultivada de Opuntia no mundo (Superintendência de Desenvolvimento do Nordeste, 2017, p. 1).

\section{Controlar e ser controlado pelas cochonilhas: uma dialética de inter-ajuste}

A O. ficus-índica é por diversos motivos o cacto mais importante para a produção agrícola não apenas no Brasil, mas ao redor do mundo, seja enquanto hospedeira para produção comercial da cochonilha-do-carmim, na produção de frutos, ou pelas suas raquetes que servem de alimento tanto a humanos quanto aos animais de criação (Food and Agriculture Organization, 2001) e ainda possuem importância material (na construção de cercas naturais) e simbólica (na construção do ideal do sujeito judeu) em Israel (Spodek et al., 2014, p. 378).

De tão amplamente difundida e facilmente adaptada a diversos contextos do mundo, a espécie chegou a ser considerada por botânicos europeus como nativa do Mediterrâneo. No entanto, estudo realizado com base no sequenciamento do DNA da 0 . ficus-índica mostrou que sua domesticação teria ocorrido na região central do atual território do México (Griffith, 2004, p. 1916); enquanto Kiesling afirma ainda que isso teria ocorrido cerca 9 mil anos atrás (Kiesling, 1998, p. 1), algo próximo do que apontam também as pesquisas de Eric O. Callen (1967, pp. 266-267), que identificou através da análise de coprólitos humanos depositados em cavernas no México a presença de Opuntia spp. na alimentação desde ao menos o período conhecido como "El Riego"4. Griffith (2004) demonstrou ainda, por meio de um modelo biogeográfico de dispersão, que ancestrais da 0 . ficus-índica teriam sido selecionados de um conjunto de espécies nativas do México e espalhadas pela Mesoamérica e Caribe através das trocas entre os diversos povos do continente muito antes da chegada dos europeus.

\footnotetext{
4 Não há consenso quanto à datação da fase “El Riego" e esta apresenta variações conforme a referência: 8500-7000 a.C. (Leroi-Gourhan, 2002); 7.000-5.000 a.C. (Jorge \& Jorge, 1991)
} 
A O. ficus-índica é planta hospedeira de várias espécies de insetos da família Dactylopiidae ${ }^{5}$ e sua domesticação está diretamente relacionada à produção da tintura carmim (Chávez-Moreno et al., 2009, p. 3343). Estudo realizado com insetos da família Dactylopiidae mostrou que as duas espécies abordadas no presente artigo ( $D$. opuntiae e $D$. coccus) pertencem a grupos de organismos diferentes - chamados em filogenética de "clados", grupos diferentes que descendem de uma mesma espécie ancestral comum (Contreras Ramos et al., 2007, p. 17). Ou seja, entre a espécie utilizada na fabricação do corante carmim e aquela que vem devastando plantações há diferenças importantes, algumas provavelmente adquiridas no processo de domesticação (Ramírez-Puebla et al., 2010, p. 1182).

No caso dos insetos da espécie $D$. opuntiae, estes "possuem um ciclo de vida mais curto e ciclos reprodutivos com um grande número de gerações por ano" (Chávez-Moreno et al., 2009, p. 3351). A espécie se reproduz com imensa rapidez, visto que em um ciclo de vida médio de 62 dias a fêmea "tem capacidade de oviposição média superior a 500 ovos" (Empresa de Pesquisa Agropecuária do Rio Grande do Norte, n.d.), com variações no tempo médio de vida "a depender principalmente da temperatura" (Chiachio, 2008, p. 12). Logo após o nascimento, durante seu primeiro ciclo de vida, as fémeas são móveis e buscam

(...) sua dispersão entre plantas e/ou raquetes hospedeiras (...) por um período de 24 horas. (...) Findo esse período, elas se juntam em grupos para o início da sucção da seiva das plantas, permanecendo sedentárias até completarem o ciclo de vida." (Empresa de Pesquisa Agropecuária do Rio Grande do Norte, n.d.).

No contexto das Américas Andina e Central pré-colombianas, plantas (Opuntia spp.) e insetos (Dactylopius spp.) tinham grande relevância para as populações locais. Raquetes novas eram utilizadas como verdura; as maduras como hospedeiras para cochonilha; os frutos eram consumidos in natura ou fermentados para dar origem a uma bebida chamada nochoctli; e ainda eram valorizadas por suas propriedades medicinais (Chávez-Moreno et al., 2009, p. 3343). Da mesma forma, os insetos Dactilopius spp. estiveram presentes em momentos diversos da vida cotidiana:

A tintura (...) era usada por pintores e escritores para pintar esculturas, madeira, códices, murais, edifícios públicos e religiosos, alimentos, bolos cerimoniais coloridos ou tortilhas, mas principalmente para algodão tingido e penas usadas para decorar roupas, além de materiais cosméticos usados por líderes militares, religiosos e governamentais (...). Na medicina, (...) foram usados para curar

\footnotetext{
5 O. ficus-índica é a hospedeira de Dactylopius spp. mais cultivada o mundo, porém, de acordo com ChávezMoreno et al. (2009: p. 3338), mais de 80 espécies de plantas hospedeiras já foram encontradas ao redor do mundo.
} 
doenças do estômago, da cabeça e do coração e foram considerados um bom tônico estimulante, sudorífico (indutor do suor), alexifármico (antídoto), febrífugo (redução da febre) e colutório (enxaguatório bucal) ... (Chávez-Moreno et al., 2009, p. 3344; tradução minha).

Contemporaneamente, as cochonilhas da espécie $D$. coccus e suas palmas hospedeiras readquiriram importância comercial no processo de produção de corantes, desta vez para a indústria de alimentos Isso porque um problema recorrente para esse setor da indústria é a alteração na cor dos produtos decorrente do processamento, transporte, temperatura, etc., e a "manutenção da cor natural do alimento se constitui num fator fundamental para o marketing do produto" (Sato et al., 1992, p. 2). Por esse motivo, a produção comercial do corante carmim atende a uma vasta gama de produtos industrializados, de alimentos a medicamentos, e sua presença pode ser verificada nas embalagens dos produtos através de códigos como E120, INS120, e ainda Natural Red 4, sendo que, no Brasil, a denominação oficial é "vermelho carmina E120" (Agência Nacional de Vigilância Sanitária, 2017).

Porém, apenas algumas décadas atrás esse cenário de relevância do produto para a indústria de alimentos passou a ser construído. Isso porque, após alguns séculos com grande importância para a balança comercial da metrópole espanhola, os corantes naturais haviam perdido valor de mercado devido ao desenvolvimento, em meados do século XIX, de corantes sintéticos (Forster \& Christie, 2013). Assim, aqueles de origem natural, como o carmim de cochonilha, só voltariam a ter maior e crescente relevância comercial a partir da década de 1960, quando foram descobertos os malefícios à saúde humana causados pelos de origem sintética (Chávez-Moreno et al., 2009, p. 3348). Como afirmam Carvalho et al. (2001), "muitas substâncias, hoje comprovadamente tóxicas, foram utilizadas como corantes para alimentos. Os inúmeros casos de toxicidade apresentados por aditivos para alimentos (...) determinaram o estabelecimento de normas em diversos países" (p. 10), o que inclui a proibição de certos corantes. Os autores ainda salientam que não apenas as normas de regulação de uso dos aditivos têm influenciado esse mercado, como também haveria uma crescente "preocupação dos consumidores com o uso de substâncias artificiais em alimentos". (p. 10)

Em outros contextos do mundo as cochonilhas, desta vez da espécie $D$. opuntiae, tiveram também papel importante ao longo do século $\mathrm{XX}$, mas neste contexto enquanto inseto predador natural de algumas espécies de Opuntia spp., ou seja, sua relevância era devido a sua capacidade destrutiva. Em artigo de 1948, afirma-se que, naquele momento, 19 dentre cerca de 20 espécies de Opuntia spp. introduzidas na África do Sul podiam ser consideradas ervas daninhas (weed) e D. opuntiae aparecia como importante instrumento no controle da praga (Pettey, 1948). Ou seja, se no semiárido brasileiro $D$. Opuntiae 
é a própria praga a destruir plantações de palmas, na África do Sul, como em outros contextos, eram as palmas que infestavam territórios e eram controladas com a inserção desses insetos predadores, ali vistos como solução para um problema.

Annecke e Moran (1978) mencionam que o controle biológico de Opuntia Megacantha, nome pelo qual já foi designada a 0 . ficus-índica, teve início em 1932, já com a inserção de $D$. Opuntiae como um predador natural. Por outro lado, em 1976, ou seja, dois anos antes da publicação mencionada acima, o mesmo autor, D. P. Annecke, do Plant Protection Research Institute, de Pretória, na África do Sul, afirma que insetos introduzidos para o controle biológico da palma (prickly pear) estavam atacando espécies úteis de Opuntia spp., que servem, tal qual no semiárido brasileiro, como ração para os animais "desde a colheita sistemática regular ao uso esporádico limitado durante as secas" (Annecke et al., 1976, p. 111; tradução minha). Desta forma, vê-se que o "problema" com a proliferação de Opuntia spp. parece ter sido resolvido nesses países, mas abre-se deste ponto outra questão: o que fazer depois disso com a população de $D$. opuntiae que agora tem sua vida nesse ambiente? Os mesmos pesquisadores afirmam ainda que já em 1943 reconhecia-se "a necessidade de controlar a cochonilha em plantações de opuntia”, mas não era possível indicar naquele momento uma forma de conter a proliferação do inseto (Annecke et al., 1976, p. 112; tradução minha). O pretenso controle humano sobre esses atores exógenos da vida na África do Sul se mostrava, portanto, um engano.

Hoje há estudos que buscam, desta vez, formas eficientes de controle para a D. Opuntiae na África do Sul e na Austrália (onde houve processo histórico parecido). Tal como afirmam Flores et al. (2013, p. 407), nesses países a O. ficusíndica "é considerada uma erva daninha menor desde que foi controlada e os benefícios das plantas têm sido cada vez mais explorados", motivo pelo qual, completam os autores, hoje "os próprios agentes de controle biológico são considerados as pragas".

No contexto da Austrália, as primeiras plantas e insetos para produção do corante carmim foram importadas do Rio de Janeiro em 1793 e não obtiveram êxito na extração da tintura, em consequência, a "Opuntia se tornou invasiva" (Chávez-Moreno et al., 2009, p. 3347; tradução minha). Pouco mais de um século depois, um artigo publicado em 1921 relatou que grandes áreas da parte Oriental do país apresentavam problemas com a expansão das palmas por territórios de agricultura (Johnston, 1921). A pretensa solução dada já naquela década foi a importação de insetos $D$. opuntiae trazidos da América do Norte para o controle biológico das plantas. Outros estudos, publicados mais tarde, registraram que na década de 1920 a $D$. opuntiae já era utilizada para controle biológico de plantas-pestes também nas Ilhas Maurício e no Sri Lanka (Sweetman, 1935), de onde foi importada para a Índia com o mesmo objetivo entre 1926 e 1927 (Manjunath, 1992, p. 16). Porém, é interessante notar que a experiência da Índia 
com o controle de Opuntia spp. através de Dactylopius spp. é ainda mais antiga, visto que em 1836 o país importou do Brasil (que desde o século anterior fazia pesquisas para a produção do corante carmim com cochonilhas mexicanas), insetos da espécie $D$. ceylonicus para o controle biológico de Opuntia vulgaris (Olckers \& Hoffmann, 1995, p. 111). 0 sucesso da experiência teria influenciado outros países a mais tarde fazerem o mesmo com essas e outras espécies.

No Brasil, se as cochonilhas já foram de interesse séculos atrás, voltaram a fomentar pesquisas sobre a extração do corante carmim na última virada de século. Em uma pesquisa realizada no país com $D$. coccus e publicada no periódico Brazilian Journal of Food Technology em 2001, os autores argumentam que, dado o contexto económico daquele momento e a proibição de muitos tipos de corantes sintéticos, seria importante olhar para a possibilidade de produção comercial do corante de cochonilha. Em suas conclusões os pesquisadores dizem que obtiveram alto rendimento com processo que pode ser "extrapolado para condições industriais" (Carvalho et al., 2001, pp. 16-17). As cochonilhas da espécie $D$. coccus utilizadas no experimento foram adquiridas no mercado já mortas e secas. Porém, trata-se de uma comunicação importante para a análise do presente artigo por demonstrar o interesse sobre a produção industrial do corante carmim no Brasil e pelo facto de sua publicação coincidir com o momento de início da infestação do semiárido pelo inseto-praga $D$. Opuntiae. Como afirmam Torres e Giorgi (2018), "desde 2001, concomitante a uma profunda seca na região, a falsa cochonilha do carmim se disseminou através da região devastando a produção de cactos palma, causando grande perda econômica e um impacto social brutal" (p. 332). Para completar, há ainda registros de que no final dos anos de 1990 havia pesquisas em andamento no IPA-Instituto de Pesquisas Agropecuárias de Pernambuco, e material publicitário em circulação que abordavam a possível produção comercial das cochonilhas no Nordeste brasileiro (Vasconcelos, 2009, p. 6).

Assim, o interesse no país durante aquela década pela produção industrial do corante parece facto difícil de contestar. Mas por outro lado, isso não é o suficiente para afirmar a origem da crise, visto que, como afirmam Silva et al. (2013): "no Brasil, a ocorrência de espécies Dactylopius é ainda amplamente debatida, especialmente no Nordeste" (p. 5237; tradução minha). Ao mesmo tempo, há também estudos que comprovam "a existência de $D$. opuntiae na cidade de Arcoverde, Pernambuco, desde 1973" (Pérez Guerra, 1991, p. 119), quase três décadas antes do início da crise. Em pesquisa acerca da biossistemática da família Dactylopiidae foram estudados materiais oriundos de diversas partes do mundo e, nesse processo, ficou comprovado que os insetos 
coletados em Arcoverde em 28 de abril de 1973 em uma Opuntia palmadora ${ }^{6}$ pertenciam à espécie $D$. opuntiae (Pérez Guerra, 1991, p. 119).

Tal informação ajuda a compreender a trajetória dos insetos $D$. opuntiae pelo semiárido brasileiro. Isso pois, Arcoverde fica poucos quilômetros ao Sul de Sertânia, cidade sede de uma Estação Experimental do IPA, e logo após, ao Norte, está Monteiro, primeira cidade do Cariri Paraibano onde a presença do inseto foi notificada e de onde a praga teria se espalhado pela Paraíba (Lopes et al., 2009). Neste período, o governador de Pernambuco era Jarbas Vasconcelos (com mandato de 1999 a 2006), que cerca de uma década mais tarde, já ocupando o cargo de senador, fez discurso e apresentou requerimento sobre a crise na região. No Requerimento $n^{\circ} 874$ de 2009 o então senador afirma que naquele momento a praga já havia superado as fronteiras do estado de Pernambuco, "colocando em risco toda bacia leiteira do Nordeste (e) (...) o que era para ser uma alternativa econômica para pequenos produtores rurais se transformou numa praga" (Vasconcelos, 2009, p. 1).

Segundo o ex-governador, o IPA teria feito um pedido ao Ministério da Agricultura para a importação do inseto para pesquisa e como a autorização não foi concedida, pesquisadores da instituição teriam sido designados para coletar amostras na região. 0 documento afirma que os insetos foram encontrados em dois municípios: Serra Talhada, em Pernambuco, e Soledade, na Paraíba. Há neste caso um desencontro entre duas afirmações presentes no documento, a primeira diz que a "cochonilha mexicana foi introduzida ilegalmente em Pernambuco", a segunda que teriam sido coletadas na própria região (Vasconcelos, 2009, pp. 1-5), o que é plausível, visto que havia presença de $D$. opuntiae nas proximidades do IPA.

No entanto, ainda segundo o ex-governador, em 1998 pesquisas sobre a produção de corante carmim com os insetos foram realizadas "em ambiente controlado" na Estação Experimental do IPA em Sertânia "verificando-se que de fato havia viabilidade pela grande eficiência na multiplicação do inseto e na produção do corante" (p. 6). Dado esse resultado, completa o documento, foi realizada uma campanha publicitária apresentando "a cochonilha como a redenção do sertanejo", o que teria influenciado produtores a levarem as plantas contaminadas, com o incentivo de autoridades locais, para suas propriedades. Este facto, segundo o argumento do ex-governador, teria dado início à crise que ao longo das décadas seguintes se espalhou pelo semiárido (Vasconcelos, 2009, p. 6).

Na resolução 004/2005 do Conselho Nacional de Segurança Alimentar e Nutricional, consta que representantes do Governo Federal já haviam sido comunicados em 2003 acerca do "risco de propagação de um foco de

\footnotetext{
${ }^{6}$ Espécie que no semiárido brasileiro é conhecida como Palmatória e se encontra com facilidade pela mata de caatinga.
} 
cochonilha de carmim ${ }^{7}$, praga da cultura da palma forrageira em dois municípios nordestinos (Sertânia - PE e Monteiro - PB)". O documento cita ainda que em 2004 a Conferência de Segurança Alimentar e Nutricional havia aprovado uma moção pela erradicação da praga, mas que até aquele momento não haviam sido "tomadas providências concretas". Por fim, o Conselho resolve recomendar "que seja iniciada ação urgente e eficaz do Governo Federal (...) em conjunto com as Secretarias de Agricultura dos Estados da Paraíba e de Pernambuco, antes que a praga se torne incontrolável" (Conselho Nacional de Segurança Alimentar e Nutricional, 2005).

Dois anos mais tarde o Ministério da Agricultura, Pecuária e Abastecimento lançaria uma Instrução Normativa objetivando o "controle da praga" (Instrução Normativa 23/2007). Porém, sem eficácia nas ações contra sua proliferação, anos mais tarde, o que se viu foi a completa destruição de lavouras de palma forrageira com graves consequências para a vida no semiárido. A solução encontrada em primeiro momento foi a substituição da 0 . ficus-índica por variedades resistentes ao inseto-praga (Silva et al., 2018, p. 517). Porém, até que a troca para o novo cultivo fosse realizada e, em pleno período de seca, os cactos se desenvolvessem, a perda das lavouras de 0 . ficus-indica veio a agravar ainda mais as consequências socioeconômicas do último período de estiagem.

Soares (2018, p. 26) ao analisar os impactos econômicos da crise na produção da palma forrageira para os produtores de Boa Vista, na Paraíba, onde a $D$. Opuntiae chegou por volta de 2011 , notou uma redução de pouco mais de $50 \%$ do rebanho de fazendas por ele estudadas. Tal redução, segundo o autor, se explica devido à dificuldade enfrentada pelos produtores para alimentar os animais. Nota-se o mesmo nos dados apresentados pela Pesquisa Pecuária Municipal, do Instituto Brasileiro de Geografia e Estatística, onde se percebe que: o rebanho de bovinos sofreu redução constante de 2013 a 2017 (de 6.272 para 4.000 cabeças), com uma pequena recuperação com a chegada do inverno de 2018 (4.650 cabeças); o rebanho de caprinos que era de 13.200 cabeças em 2009 foi reduzido ano a ano e chegou a menos da metade em 2013 (6.000 cabeças), em 2018 esse número passou para 8.600 cabeças; enquanto o rebanho de ovinos teve queda entre 2011 e 2012 (de 5.100 para 3.000 cabeças), com recuperação no período seguinte, sendo registradas 6.000 cabeças em 2018, ano em que teve fim o período de estiagem.

A D. Opuntiae vem se tornando uma perigosa praga não apenas no Brasil, mas em várias partes do mundo, como até mesmo no México, de onde é natural, mas já se tornou praga nas zonas áridas do Norte do país (Flores-Hernández et

\footnotetext{
70 documento erra grosseiramente o nome do inseto-praga que naquele momento iniciava a infestação pelo Nordeste. 0 mesmo menciona a propagação de "Dactyphius coccus" (sic), espécie essa que sequer existe. Há confusão quanto ao nome da espécie, o correto seria Dactylopius, e quanto a espécie em si, a qual seria $D$. opuntiae, ao invés de $D$. coccus. $O$ facto de a resolução errar em tal menção dá sinais claros de desinformação das instituições sobre a crise que se instaurava.
} 
al., 2006, p. 98). Selma Ülgentürk e Sema Şişman Hocaali (2019) registraram também a presença de $D$. opuntiae e sua rápida proliferação na República Turca de Chipre do Norte e, desde sua primeira notificação em 2017, as plantações de O. ficus-índica na região de Maraş já haviam sido completamente destruídas. Em Israel a primeira notificação ocorreu em 2013 no Vale do Hula, região agrícola no Norte do país (Spodek et al., 2014); e na vizinha Jordânia o primeiro registro veio em 2018 já com uma grande infestação na região Norte se direcionando para o centro (Bader \& Abu-Alloush, 2018). No Marrocos o primeiro registro ocorreu em 2015, $120 \mathrm{~km}$ a noroeste de Marrakesh (Bouharroud et al., 2016), e pesquisa publicada em 2019 afirma que desde então o inseto-praga se espalhou por outras regiões, como "Doukkala, Rhamna, Bengrir, Abda, Azilal, Benimellal, Taourirt, Haouz e Chaouia, onde dezenas de milhares de hectares de cactos foram destruídos, causando enormes perdas socioeconômicas e ambientais" (El Aalaoui et al., 2019). Por fim, Mazzeo et al. (2019) alertam para o grande risco que toda região do Mediterrâneo corre com a disseminação do inseto-praga, que teria presença já registrada na Espanha e na França (Mazzeo et al., 2019, p. 60).

As alternativas de controle adotadas até o momento giram em torno da substituição das espécies de cactos (Silva et al. 2018: 517), como ocorreu no Brasil, o combate com produtos químicos ou naturais (Brito et al. 2008) e a inserção no ambiente de inimigos naturais para o controle biológico da espécie (Garziera et al., 2008; Lima et al., 2011). Segundo Carvalho et al. (2014), no Brasil a principal alternativa implantada ainda no início da crise se deu através do uso de inseticidas, algo que é prejudicial à saúde dos produtores e dos animais da criação, além do facto de os inseticidas provocarem a mortalidade de outros insetos, mesmo os inimigos naturais do próprio inseto-praga, podendo gerar novos desequilíbrios ecológicos (Brito et al. 2008, p. 4).

Com o intuito de buscar outra possibilidade de manejo da praga, Carvalho et al. (2014) demonstraram que para eliminar as colónias de $D$. opuntiae das plantas é importante antes eliminar a camada cerosa branca que as cobre e protege os insetos dos efeitos do sol e de alguns predadores, o que pode ser feito através da aplicação da mistura de água e sabão em pó ou detergente neutro (Carvalho et al., 2014). Neste mesmo sentido, há pesquisas que mostram que as condições do clima possuem importante papel no manejo do $D$. opuntiae. As chuvas lavam para fora das raquetes a maior parte das colónias dos insetos (Moran et al., 1987), enquanto as baixas temperaturas reduzem sua capacidade de reprodução e sobrevivência (Foxcroft \& Hoffmann 2000, p. 2; Goeden \& Lauda, 1976; Hosking et al., 1994, p. 247). Tais factos deixam claro que os seguidos períodos de seca no Nordeste brasileiro facilitaram a proliferação do insetopraga no início deste século, com destaque para a última estiagem com duração de sete anos (2011 - 2018). Além do fato de que, no Cariri Paraibano, a média pluviométrica não chega a atingir $400 \mathrm{~mm}$ ao ano, mesmo nas estações chuvosas (Cohen \& Duké, 199, p. 49). 
Ou seja, se as chuvas e as temperaturas amenas são prejudiciais à reprodução da $D$. opuntiae, as condições do tempo climático encontradas em princípios da mais longa seca da história do Nordeste brasileiro, quando os registros anuais não superaram 100 mm (Zani, 2019, p. 166), foram perfeitas para sua proliferação sem manejo efetivo. Facto esse que coloca um importante alerta quanto às perspectivas futuras em um contexto de mudanças climáticas, visto que, como afirma Magalhães (2016), "a frequência e intensidade de secas na região Nordeste deve crescer junto com a duração dos períodos de seca" ( $p$. 17; tradução minha).

Quanto à utilização de predadores naturais do inseto-praga, destaca-se a ação do Cryptolaemus montrouzieri, ou Joaninha australiana. Espécie exótica que foi implantada no Brasil pela Embrapa-Empresa Brasileira de Pesquisa Agropecuária, para fins de controle biológico de cochonilhas e pulgões (Sanches \& Carvalho, 2010). Um estudo mostrou que os insetos importados possuem grande capacidade de predação de $D$. Opuntiae e têm fácil reprodução em ambiente artificial (Garziera et al., 2008). Porém, os autores frisam que ainda são necessários estudos sobre "sua capacidade de dispersão e sobrevivência no clima semiárido" (Garziera et al., 2008, p. 67). Além disso, o artigo não menciona, mas é imprescindível pensar o impacto que qualquer espécie exótica possa causar no ecossistema local. Do contrário, os insetos continuarão sendo vistos enquanto objetos manipuláveis segundo os interesses humanos, até que eles próprios se mostrem atores livres contrariando as pretensões humanas.

Da mesma forma, os autores afirmaram na época da publicação do referido artigo não haver na região "inimigos naturais específicos" para o insetopraga, o que justificaria a implementação do Cryptolaemus montrauzieri. Porém, estudo realizado em 2007 no semiárido pernambucano e publicado apenas em 2011 (Lima et al., 2011) identificou cinco espécies predadoras nativas pertencentes a três diferentes famílias: Coccidophilus citricola (Coccinellidae), Exochomus sp. (Coccinellidae), Zagreus bimaculosus (Coccinellidae), Salpingogaster sp. (Syrphidae) e Cybocephalus sp. (Nitidulidae).

Neste sentido, é importante mencionar que um dos principais contrastes observados entre a seca e a estação chuvosa no semiárido brasileiro é o ressurgimento da flora nativa e o retorno de animais, assim como a retomada do plantio de outras culturas nos intervalos entre as palmas (Zani, 2019, p. 156). Em outras palavras, em tempos de chuva amplia-se a biodiversidade local e isso reduz a proliferação de pragas, tal como afirmam Silva et al. (2015):

0 espaçamento menos adensado (entre as palmas) permite 0 consórcio com outras culturas, tais como milho e feijão, além disso, facilita os tratos culturais, importantes para a agricultura familiar do semiárido, e minimiza os riscos de pragas e doenças na cultura". ( $p$. 157). 
Assim, "o espaçamento tradicional de aproximadamente 2,00 m x 1,00 m, em consórcio com outras culturas como: milho, feijão e algodão" (Galvão Junior et al., 2014, p. 81), era uma forma de proteção e prevenção de pragas, mas que foi desfeita na década de 1980 pela praga do bicudo nos algodoeiros ${ }^{8}$ e sempre que a seca se prolonga e inviabiliza outras culturas que não a da palma forrageira. Dito de outra forma, afirmam Silva et al. (2018, p. 517), a monocultura da O. ficusindica teria facilitado a disseminação do inseto-praga, com "consequências desastrosas".

Bem como, pode-se observar que a 0 . palmadora, encontrada no interior da mata de caatinga, mesmo sendo hospedeira de D. opuntiae (Portillo, 2008, p. 56) e havendo o registro do inseto coletado em plantas da espécie em 1973 (Pérez Guerra, 1991, p. 119) não foi atingida pela mesma devastação que as plantações de 0 . ficus-índica. Após a infestação ter devastado praticamente toda área cultivada, na sequência daquele período de seca a 0 . palmadora não apenas não havia sido atingida pelo inseto como era encontrada na mata e utilizada por muitos sitiantes como ração animal, situação presenciada quase que diariamente durante o trabalho de campo no auge da estiagem. Facto esse que leva a outro alerta, desta vez quanto à contínua degradação da mata de caatinga no Nordeste brasileiro, a desertificação de parte do ambiente e os consequentes desequilíbrios ecológicos (Alves et al., 2009; Souza et al., 2015)

Já no sentido da alternativa de substituição da 0 . ficus-índica por espécie resistente, o INSA-Instituto Nacional do Semiárido anunciou em 2013 o investimento de 500 mil reais ( $€ 1.610 .000,00$ euros, em valores de 2013) na instalação de 26 campos de pesquisa na Paraíba com o objetivo de estudar e entregar aos produtores variedades resistentes à praga (Instituto Nacional do Semiárido, 2013). A espécie introduzida em Boa Vista, como em todo Cariri Paraibano, como já mencionado, foi a 0 . stricta, que, como logo perceberam os produtores, é de difícil manejo, devido à grande quantidade de pelos e espinhos (Cavalcanti et al., 2008, p. 174), fato que influencia ainda na redução do consumo por ovinos e caprinos - de $1 \mathrm{Kg} /$ dia de 0 . ficus-índica para 0,64 Kg/dia de 0 . stricta (Cavalcanti et al., 2008, p. 176). Mesmo com a desvantagem, essa foi a alternativa de maior efetividade, tendo garantido o gradual restabelecimento do cultivo da palma forrageira nas zonas afetadas (Instituto Nacional do Semiárido, 2013).

\section{Conclusão}

\footnotetext{
8 A cultura do algodão que já foi chamada de "ouro branco" do Nordeste (Guedes, 2006), depois da devastação provocada pelo bicudo-do-algodoeiro (Anthonomus grandis) encontra-se praticamente abandonada (Cohen e Duqué, 2001, p. 181). Segundo o Censo Agropecuário do Instituto Brasileiro de Geografia e Estatística, a produção de algodão em caroço no estado da Paraíba que já foi de 71.770 toneladas em 1975 chegou a apenas 107 toneladas em 2006.
} 
O que fica claro a partir de tais resultados de pesquisas é que não há solução isolada para o problema. Tal como defendem Brito et al. (2008, p. 2), a alternativa passa pela integração de diferentes práticas. A técnica mencionada pelo autor é conhecida como MIP-Manejo Integrado de Pragas e, como definem Metcalf \& Luckman (Eds.) (1994), já em seu primeiro passo, "envolve o uso de táticas de gerenciamento múltiplo ecologicamente corretas para uma única classe de pragas" (p. 546; tradução minha). Ou seja, é preciso considerar a integração de tudo aquilo que compõe a vida, entre humanos e não-humanos, em determinado ambiente, pois, ao desconsiderar tal realidade integrada, as pretensas soluções tendem a repetir estratégias do passado (no mínimo questionáveis). Visto que, se há inúmeros estudos defendendo ao longo do século XX a grande capacidade dos insetos $D$. opuntiae para o controle biológico de espécies Opuntia spp., em pesquisa mais recente, Flores et al. (2013) já mostram uma mudança nesse panorama, pois hoje a preocupação se torna para a recuperação, ao menos, de parte das plantações de palma, e o manejo da população do inseto, que então passa a ser visto enquanto praga. Como afirmam os autores:

D. opuntiae também foi relatado como um agente de controle biológico, onde o cacto palma era uma planta invasora, mas as populações de 0 . ficus-indica agora são altamente valorizadas na África e na Austrália, onde os próprios agentes de controle biológico são considerados pragas (Flores et al., 2013, p. 407; tradução minha).

Tal inversão no papel exercido pelo $D$. opuntiae demonstra que o pretenso controle humano sobre a malha da vida, como mostra a base teórica proposta por Tim Ingold (2012, p. 35), é apenas aparente. Ou, no caminho do que afirma Bruno Latour (1994, pp. 28-29), se antes os insetos Dactylopius spp. eram tidos como instrumentos na produção de corante carmim ou no controle de Opuntia spp., mostraram-se "cidadãos livres" e deixaram sua "assinatura trémula" na história do semiárido brasileiro, como também em outras partes do mundo.

A presunção antropocêntrica, no caso do semiárido brasileiro, se mostra de forma nítida e eloquente nas repetidas, e quase sempre fracassadas, tentativas de se propor uma solução tecnológica para o que historicamente foi tido como o problema da seca. Como se um fenómeno climático natural fosse o problema a ser solucionado e não o abandono político e económico em que vive a população local. De tempos em tempos algo cerceia uma antiga organização da vida no semiárido brasileiro dilapidando formas de vida e de viver do lugar. Alternativas são postas como a salvação do povo nordestino, mas, com o passar do tempo, acabam por causar danos muito maiores que as soluções a que se prometiam. 


\section{Referências}

Alves, J. J. A., Araújo, M. A. de, \& Nascimento, S. S. do. (2009). Degradação da Caatinga: uma investigação ecogeográfica. Revista Caatinga, 22(3), pp. 126135.

Annecke, D.P., Burger, W.A., \& Coetzee, H. (1976). Pest status of Cactoblastis cactorum (Berg) (Lepidoptera: Phycitidae) and Dactylopius opuntiae (Cockerell) (Coccoidea: Oactylopiidae) in spineless opuntia plantations in South Africa. Journal of the Entomological Society of Southern Africa, 39(1), pp. 111-116.

Annecke, D. P. \& Moran, V. C. (1978). Critical reviews of biological pest control in South Africa. Journal of the Entomological Society of Southern Africa, 41(2), pp. 161-188.

Agência Nacional de Vigilância Sanitária. (2017). Resolução da Diretoria Colegiada - RDC N²01, Diário Oficial da União nº 248 de 28 de dezembro de 2017.

Bader, A. M. K. \& Abu-alloush, A. H. (2019). First Record of the Cochineal Scale Insect, Dactylopius opuntiae (Cockerell) (Hemiptera: Dactylopiidae). Jordan Journal of Biological Sciences, 1(2), pp. 155-159

Bouharroud, R., Amarraque, A., \& Qessaoui, R. (2016). First report of the Opuntia cochineal scale Dactylopius opuntiae (Hemiptera: Dactylopiidae) in Morocco. EPPO Bulletin, 46(2), pp. 308-310.

Brito, C. H., Lopes, E. B.; Albuquerque, I., Batista, J. (2008). Avaliação de produtos alternativos e pesticidas no controle da cochonilha-do-carmim na Paraíba. Revista de Biologia e Ciências da Terra, 8(2), pp. 1-5.

Bueno, V. H. P., Junior, J., Junior, A. M., \& Silveira, L. D. (2015). Controle biológico e manejo de pragas na agricultura sustentável. Departamento de Entomologia, Universidade Federal de Lavras. Retirado de: http://www.den.ufla.br/attachments/article/75/ApostilaCB\%20\%28final\%29. pdf

Burnett, A. (2017). A "saga" político-ecológica da algaroba no semiárido brasileiro. Revista de Estudos Sociais, 19(38), pp. 148-175. 
Callen, E. O. (1967). Analyses of Tehuacán coprolites. Douglas S. Byers (Ed.), The prehistory of the Tehuacán Valley, vol 1: Environment and subsistence (pp. 261289). University of Texas Press: Andover.

Carvalho, P. R. N., Collins, C. H., \& Carvalho, C. R. L. (2001). Extração e produção do corante carmim de cochonilha. Brazilian Journal of Food Technology, 4, pp. 9-17.

Carvalho, R.A.; Lopes, E.B., Silva, A. C., Leandro, R.S., \& Campos, V.B. (2014). Controle alternativo da cochonilha-do-carmim em palma forrageira no cariri paraibano. Brasília: MMA - Ministério do Meio Ambiente.

Cavalcanti, M. C. A., Batista, Â. M. V., Guim, A., de Andrade Lira, M., Ribeiro, V. L., \& Neto, A. C. R. (2008). Consumo e comportamento ingestivo de caprinos e ovinos alimentados com palma gigante (Opuntia ficus-indica Mill) e palma orelha-de-elefante (Opuntia sp.). Acta Scientiarum Animal Sciences, 30(2), pp. 173-179.

Chávez-Moreno, C. K., Tecante, \& A., Casas, A. (2009). The Opuntia (Cactaceae) and Dactylopius (Hemiptera: Dactylopiidae) in Mexico: a historical perspective of use, interaction and distribution. Biodiversity and Conservation, 18(13), pp. 3337-3355.

Chiacchio, F. P. B.. (2008). Incidência da cochonilha do carmim em palma forrageira. Bahia Agrícola, 8(2), pp. 12-14.

Cohen, M. \& Duqué, G. (2001). Les Deux Visage du Sertão : Stratégies paysannes face aux sécheresses (Nordeste du Brésil). Paris: Institut de recherche pour le Développement - IDR Éditions.

Conselho Nacional de Segurança Alimentar e Nutricional. (2005). Resolução CONSEA No. 004/2005. Brasília.

Contreras Ramos, A. (2007). La sistemática, base del conocimiento de la biodiversidad. Pachuca - México: UAEH - Universidad Autónoma del Estado de Hidalgo.

Cruz, A. J. (2007). Pigmentos e corantes das obras de arte em Portugal, no início do século XVII, segundo o tratado de pintura de Filipe Nunes. Conservar património, 6, pp. 39-51. 
El Aalaoui, M., Bouharroud, R., Sbaghi, M., El Bouhssini, M., \& Hilali, L. (2019). Predatory potential of eleven native Moroccan adult ladybird species on different stages of Dactylopius opuntiae (Cockerell) (Hemiptera: Dactylopiidae). EPPO Bulletin 0, pp. 1-6.

Empresa de Pesquisa Agropecuária do Rio Grande do Norte. (n.d.). Cochonilha do Carmim na Palma Forrageira: conheça a praga e as estratégias de controle. Impresso. Retirado de: https://www.embrapa.br/busca-de-publicacoes//publicacao/1094393/cochonilha-do-carmim-na-palma-forrageira-conheca-apraga-e-as-estrategias-de-controle.

Food and Agriculture Organization. (2001). Cactus (Opuntia spp.) as forage. Plant Production and Protection Paper. $\mathrm{n}^{\circ} 169$.

Ferraz, M. (2007). A rota dos estudos sobre a cochonilha em Portugal e no Brasil no século XIX: caminhos desencontrados. Química Nova, 30(4), pp. 10321037.

Flores, A., Olvera, H., Rodríguez, S., \& Barranco, J. (2013). Predation potential of Chilocorus cacti (Coleoptera: Coccinellidae) to the prickly pear cacti pest Dactylopius opuntiae (Hemiptera: Dactylopiidae). Neotropical entomology, 42(4), pp. 407-411

Flores-Hernández, A., Murillo-Amador, B., Rueda-Puente, E. O., Salazar-Torres, J. C., García-Hernández, J. L., \& Troyo-Diéguez, E. (2006). Reproducción de cochinilla silvestre Dactylopius opuntiae (Homóptera: Dactylopiidae). Revista mexicana de biodiversidad, 77(1), pp. 97-102.

Forster, S. V \& Christie, R. M. (2013). The significance of the introduction of synthetic dyes in the mid 19th century on the democratisation of western fashion. JAIC - Journal of the International Colour Association, 11, pp. 1-17.

Foxcroft, L. C. \& Hoffmann, J. H. (2000). Dispersal of Dactylopius opuntiae Cockerell (Homoptera: Dactylopiidae), a biological control agent of Opuntia stricta (Haworth.) Haworth. (Cactaceae) in the Kruger National Park. Koedoe, 43(2), pp. 1-5.

Galvão Júnior, J. G. B., Silva, J. B. A., Morais, J. H. G., \& de Lima, R. N. (2014). Palma forrageira na alimentação de ruminantes: cultivo e utilização. Acta Veterinaria Brasilica, 8(2), pp. 78-85. 
Garziera, L., de Lima M. S., Lopes, F. S. C., da Silva, L. D., \& Paranhos, B. A. J. (2008). Eficiência de Cryptolaemus montrouzjeri (Mulsant) (Coleoptera: Coccinelidae) na predação da cochonilha-do-carmim (Dactylopius opuntiae). In: Jornada de Iniciação Científica da Embrapa Semi-árido (pp. 63-68). Petrolina - Pernambuco.

Griffith, M. P. (2004). The origins of an important cactus crop, Opuntia ficusindica (Cactaceae): new molecular evidence. American Journal of Botany, 91(11), pp. 1915-1921.

Goeden, R. D. \& Louda, S. M. (1976). Biotic interference with insects imported for weed control. Annual Review of Entomology, 21(1), pp. 325-342.

Guedes, K. A. (2006). O ouro branco abre caminho: o algodão e a modernização do espaço urbano da Cidade da Parahyba (1850-1924). Dissertação de Mestrado. Universidade Federal do Rio Grande do Norte.

Harman, G. (2009). Prince of networks: Bruno Latour and metaphysics. Melbourne - Austrália: Re. Press.

Hosking, J. R., Sullivan, P. R., \& Welsby, S. M. (1994). Biological control of Opuntia stricta (Haw.) Haw. var. stricta using Dactylopius opuntiae (Cockerell) in an area of New South Wales, Australia, where Cactoblastis cactorum (Berg) is not a successful biological control agent. Agriculture, ecosystems \& environment, 48(3), pp. 241-255.

Instituto Brasileiro de Geografia e Estatística. (1970). Censo Agropecuário. Retirado de: https://sidra.ibge.gov.br/Tabela/281

Instituto Brasileiro de Geografia e Estatística. (2006). Censo Agropecuário. Retirado de: https://sidra.ibge.gov.br/Tabela/281

Instituto Brasileiro de Geografia e Estatística. (2011 - 2018). Pesquisa Pecuária Municipal. Retirado de: https://sidra.ibge.gov.br/Tabela/3939

Ingold, T. (2012). Trazendo as coisas de volta à vida: Emaranhados criativos em um mundo de materiais. Horizontes Antropológicos, 18(37), pp. 25-44.

Ingold, T. (2015). Estar Vivo: ensaios sobre movimento, conhecimento e descrição. Tradução de Fábio Creder. Petrópolis, RJ: Vozes 
Instituto Nacional do Semiárido. (2013). Boletim Informativo, ano I, nº 02, 18 a 22 de fevereiro de 2013.

Johnston, T. H. (1921). Biological Control of the Prickly-Pear Pest. Queensland Agricultural Journal, 16(2), pp. 65-68.

Jorge, S. O. \& Jorge, V. O. (1991). Incursões na Pré-história. Porto: Fundação Eng. António de Almeida.

Kiesling, R. (1998). Origen, domesticación y distribución de Opuntia ficus-indica. Journal of the Professional Association for Cactus Development, 3, pp. 50-59.

Latour, B. (1994). Jamais fomos modernos: ensaios de antropologia simétrica. Tradução de Carlos Irineu da Costa. Rio de Janeiro: Ed. 34.

Latour, B. (2012). Reagregar o Social: uma introdução à teoria do ator-rede. Salvador - Bahia: EdUFBA.

Leroi-Gourhan, A. (2002). La prehistoria en el mundo. Trad. Francisco Gracía. Madrid: Ediciones AKAL.

Lima, M. S., Da Silva, D. M., HM, F., Ferreira, W. M., Silva, L. D., \& Paranhos, B. A. (2011). Predadores associados a Dactylopius opuntiae (Hemiptera: Dactylopiidae) em palma forrageira no estado de Pernambuco, Brasil. Revista Chilena de Entomologia, 36, pp. 51-54.

Lopes, E. B., Albuquerque, I. C., Brito, C. H., \& Luna Batista, J. (2009). Velocidade de infestação e dispersão de Dactylopius opuntiae Cockerell, 1896 em palma gigante na Paraíba. Engenharia Ambiental: Pesquisa e Tecnologia, 6(1), pp. 196-205.

Lopes, E. B., Brito, C. D., Albuquerque, I. C., \& Batista, J. L. (2010). Seleção de genótipos de palma forrageira (Opuntia spp. e Nopalea spp.) resistentes à cochonilha-do-carmim (Dactylopius opuntiae Cockerell, 1929) na Paraíba, Brasil. Engenharia Ambiental-Pesquisa e Tecnologia, 7(1), pp. 204-215.

Magalhães, A. R. (2016). Life and Drought in Brazil In: E. Denys et al. (orgs.) Drought in Brazil: Proactive Management and Policy. NY: CRC Press - Taylor \& Francis Group. 
Manjunath, T. M. (1992). Biological control of insect pests and weeds in India: Notable successes. In Y. Hirose (Ed.), Biological control in South East Asia (pp. 11-21). Tokyo: Kyushu Univ Press/IOBC/SEARS.

Marques, L. (2015). Capitalismo e colapso ambiental. Campinas, SP: Editora da Unicamp.

Mazzeo, G., Nucifora, S., Russo, A., \& Suma, P. (2019). Dactylopius opuntiae, a new prickly pear cactus pest in the Mediterranean: an overview. Entomologia Experimentalis et Applicata, 167(1), pp. 59-72.

Metcalf, R. L. \& Luckmann, W. H. (eds.). (1994). Introduction to insect pest management. New York: John Wiley \& Sons.

Ministério da Agricultura, Pecuária e Abastecimento. 2007. Instrução Normativa $N^{\circ} 23$, de 29 de maio de 2007. Retirado de: http://www.agricultura.gov.br/assuntos/sanidade-animal-e-vegetal/ sanidade-vegetal/arquivos-prevencao/IN23_2007CochonilhadoCarmim.pdf

Miranda, J. E. \& Rodrigues, S. M. M. (2015). História do bicudo no Brasil. In Instituto Mato-grossense do Algodão - IMAmt, 0 bicudo-do-algodoeiro (Anthonomus grandis BOH., 1843) nos cerrados brasileiros (pp. 10-44). Cuiabá, MT: Instituto Mato-Grossense do Algodão.

Moran, V. C., Hoffmann, J. H., \& Basson, N. C. J. (1987). The effects of simulated rainfall on cochineal insects (Homoptera: Dactylopiidae): colony composition and survival on cactus cladodes. Ecological Entomology, 12(1), pp. 51-60.

Neves, F. C. (2001). Getúlio e a seca: políticas emergenciais na era Vargas. Revista Brasileira de História, 21(40), pp. 107-129.

Olckers, T. \& Hoffmann, J. H (1995). Eighty years of biological weed control in South Africa: how far have we come? Veld \& Flora 81, pp. 110-114.

Paixão, F. (2007). Simbolismo e cor nos bordados de Castelo Branco: alquimias de um jardim para a cama dos noivos. AA.VV., Jardins dos Noivos (pp. 3-11). Lisboa: Naturarte, 8.

Pegado, C. M. A., Andrade, L. A. D., Félix, L. P., \& Pereira, I. M. (2006). Efeitos da invasão biológica de algaroba-Prosopis juliflora (Sw.) DC. sobre a composição e a estrutura do estrato arbustivo-arbóreo da caatinga no Município de Monteiro, PB, Brasil. Acta Botanica Brasilica, 20(4), pp. 887-898. 
Pérez Guerra, G. M. del C. (1991). Biosystematics of the family Dactylopiidae (Homoptera: Coccinea) with emphasis on the life cycle of Dactylopius coccus Costa. Dissertação de doutorado em Entomology. Virginia Polytechnic Institute and State University.

Pettey, F. W. (1948). The biological control of prickly pears in South Africa. Scientific Bulletin, 271 pp. (pp. 1-163). Department of Agriculture of the Union of South Africa.

Portillo, L. (2008). Los hospederos norte y sudamericanos de Dactylopiidae. In A. Vigueras, C. Llanderal, D. Zetina \& L. Portillo. Grana cochinilla y colorantes naturales (pp. 52-57). Texcoco: Colegio de Postgraduados.

Ramírez-Puebla, S. T., Rosenblueth, M., Chávez-Moreno, C. K., Pereira de Lyra, M. C., Tecante, A., \& Martínez-Romero, E. (2010). Molecular phylogeny of the genus Dactylopius (Hemiptera: Dactylopiidae) and identification of the symbiotic bacteria. Environmental entomology, 39(4), pp. 1178-1183.

Sanches, N. F. \& Carvalho, R. S. (2010). Procedimentos para manejo da criação e multiplicação do predador exótico Cryptolaemus montrouzieri. Embrapa Mandioca e Fruticultura - Circular Técnica (INFOTECA-E).

Santos, E. A. V., Holanda, H. T. S., Pereira, F. C., \& Batista, D. C. (2017). Biometria da palma forrageira orelha de elefante (Opuntia stricta) cultivada com rejeito de mica e outros compostos orgânicos. Il Congresso Internacional das Ciências Agrárias. Aprsentação em conferência. Retirado de: https://www.researchgate.net/publication/326516357_BIOMETRIA_DA_PAL MA_FORRAGEIRA_ORELHA_DE_ELEFANTE_Opuntia_stricta_CULTIVADA_CO M_REJEITO_DE_MICA_E_OUTROS_COMPOSTOS_ORGANICOS

Sato, G. S., Chabaribery, D., Maia, M. L., de Carvalho, F. C., Negri Neto, A., \& Marques, S. A. (1992). A. tendência de mercado para corantes na indústria de alimentos. Agicultura em São Paulo, 39(1), pp. 1-50.

Silva, D. M. P., Mergulhão, A. C., Medeiros, L. V., Figueiredo, M. V. B., \& Burity, H. A. (2013). Genetic variability of Dactylopius opuntiae (Hemiptera, Dactylopiidae) on forage cactus in northeast Brazil. Genetics and Molecular Research, 12(4), pp. 5236-5246.

Silva, R. R. \& Sampaio, E. V. S. B. (2015). Palmas forrageiras Opuntia fícus-indica e Nopalea cochenillifera: sistemas de produção e usos| Opuntia fícus-indica 
and Nopalea cochenillifera cacti: production systems and uses. Revista Geama, 1(2), pp. 151-161.

Silva, R. C., Ferreira, M. A., Oliveira, J. C. V., Santos, D. C., Gama, M. A. S., Chagas, J. C. C., ... \& Pereira, L. G. R. (2018). Orelha de Elefante Mexicana (Opuntia stricta [Haw.] Haw.) spineless cactus as an option in crossbred dairy cattle diet. South African Journal of Animal Science, 48(3), pp. 516-525.

Soares, E. R. A. (2018). Indicadores sociais e produtivos da palma forrageira, num recorte geográfico do município de Boa Vista-PB. Trabalho de Conclusão de Curso / Graduação em Geografia. Campina Grande: Universidade Estadual da Paraíba.

Souza, B. I., Artigas, R. C., \& Lima, E. R. V. (2015). The Caatinga and desertification. Mercator, 14(1), pp. 131-150.

Spodek, M., Ben-Dov, Y., Protasov, A., Carvalho, C. J., \& Mendel, Z. (2014). First record of Dactylopius opuntiae (Cockerell) (Hemiptera: Coccoidea: Dactylopiidae) from Israel. Phytoparasitica, 42(3), pp. 377-379.

Superintendência de Desenvolvimento do Nordeste. (2017). Nota Complementar no 07 de 2017/CGDS/DPLAN/SUDENE. Retirado de: http://www.sudene.gov.br/images/2017/arquivos/Item_1.7.4_-_Nota_ T\%C3\%A9cnica_Complementar_n\%C2\%BA_07-2017-CGDS-DPLANSUDENE.PDF

Sweetman, H. L. (1935). Successful examples of biological control of pest insects and plants. Bulletin of entomological research, 26(3), pp. 373-377.

Torres, J. B. \& Giorgi, J. A. (2018). Management of the false carmine cochineal Dactylopius opuntiae (Cockerell): perspective from Pernambuco state, Brazil. Phytoparasitica, 46(3), pp. 331-340.

Ülgentürk, S., \& Hocaali, S. S. (2019). Pest Status of Dactylopius Opuntiae (Cockerell)(Hemiptera: Dactylopiidae) and New Records of Scale Insects from Northern Turkish Republic of Cyprus. Munis Entomology \& Zoology, 14(1), pp. 294-300.

Vasconcelos, J. (2009). Requerimento nº 874 de 2009. Brasília: Senado Federal.

Velho, O. (2012). Posfácio. In C Steil \& I. Carvalho (orgs.), Cultura, percepção e ambiente. Diálogos com Tim Ingold (pp. 227-231). São Paulo: Terceiro Nome. 
Zani, M. A. (2019). Bravo: a água em um emaranhado de vidas no Cariri Paraibano. Tese de doutorado. Universidade Estadual de Campinas. 